\title{
Ramsay Hunt syndrome: long-term facial palsy outcome assessed face-to-face by three different grading scales and compared to patient self-assessment
}

\author{
Mervi Kanerva $^{1}$ [D $\cdot$ Sanna Jones ${ }^{2} \cdot$ Anne Pitkaranta $^{1}$
}

Received: 28 February 2020 / Accepted: 27 July 2020 / Published online: 3 August 2020

(c) The Author(s) 2020

\begin{abstract}
Purpose To determine the long-term facial palsy outcome of Ramsay Hunt Syndrome by face-to-face grading by HouseBrackmann Grading System, Facial Nerve Grading System 2.0, and Sunnybrook Facial Grading System concomitantly. To compare the applicability of the grading scales. To compare patients' self-assessed facial palsy outcome results to gradings performed by the investigator. To compare the face-to-face assessed facial palsy outcome to the initial palsy grade.

Methods Fifty-seven patients self-assessed their facial palsy outcome and came to a one-time follow-up visit. The palsy outcome was graded by one investigator using the three above-mentioned grading systems concomitantly. The median time from syndrome onset to follow-up visit was 6.6 years.

Result A good long-term face-to-face assessed palsy outcome was enjoyed by $84 \%$ of the patients. Trying to assess only one House-Brackmann grade to represent the palsy outcome was impossible for most patients. Facial Nerve Grading System 2.0 worked better, but needed adjustments and certain sequelae findings needed to be neglected for it to be executable. The Sunnybrook system worked the best. Nearly $20 \%$ of the patients assessed themselves differently from the investigator: both better and worse.

Conclusion The Sunnybrook scale was the most applicable system used. With antiviral medication, the outcome of facial palsy in Ramsay Hunt syndrome starts to resemble that of Bell's palsy and emphasizes the importance of recognizing the syndrome and treating it accordingly. The results give hope to patients instead of the gloomy prospects that have stigmatized the syndrome.
\end{abstract}

Keywords House-brackmann grading system $\cdot$ Facial nerve grading system $2.0 \cdot$ Sunnybrook facial grading system $\cdot$ Facial paralysis $\cdot$ Herpes zoster oticus $\cdot$ Facial nerve

\section{Introduction}

Ramsay Hunt syndrome (RHS) involves peripheral facial palsy (FP) and herpes blisters in the head and neck area. In addition to the facial nerve (cranial nerve VII), the vestibulocochlear nerve (cranial nerve VIII) is frequently affected, which causes hearing loss, tinnitus, and/or vertigo [1]. All cranial nerves (V, VIII, IX, X, more rarely III, XI, XII) and

Mervi Kanerva

mervi.kanerva@gmail.com

1 Department of Otorhinolaryngology, Head and Neck Surgery, Helsinki University Hospital and University of Helsinki, PO Box 263, 00029 Helsinki, Finland

2 Occupational Health, Helsinki, Finland cervical nerves $(\mathrm{C} 2, \mathrm{C} 3, \mathrm{C} 4)$ that communicate with facial nerve can be affected [2-4]. The cause of RHS is reactivation of latent varicella-zoster virus (VZV) $[1,5,6]$. The incidence of RHS has varied among studies and has been estimated to be from 1 to $5 / 100,000 / y e a r$ or $4 \%$ to $18 \%$ of all FP cases [1, 7-10].

Even in one-third of RHS cases, blisters follow FP [10, 11] making the diagnosis of RHS impossible at the time of FP onset. Clinicians must be alert to remember the syndrome and inform patients of this possibility.

Published studies on RHS FP outcomes are scarce, including mostly retrospective chart studies, and lacking long follow-up periods; few follow the patients even up to 1 year $[7,12,13]$. The only reported prospective study including RHS patients with 1-year follow-up is from prior to when medical treatment was offered to these patients 
[7]. With retrospective studies and experience in relation to medications used in shingles, it is a widely accepted view that antiviral medication combined with corticosteroids is beneficial in RHS [14-17].

At present, we lack a reliable way to grade FP. Objective methods are being developed, but are not yet widely clinically used. The most used subjective method is the House-Brackmann grading scale (HB) [18], with six grades, where I is normal facial function and VI total paralysis. Each grade represents a certain voluntary movement status (as one for the whole face, not graded regionally), resting symmetry, and synkineses as defined in the scale instructions. $\mathrm{HB}$ is a gross scale, not originally intended for specifying the movements of different facial areas or delicate sequelae. Therefore, it is known to be poorly suitable to grade precise and detailed information of FP or record FP surgery outcomes [19-21]. A revised version, Facial Nerve Grading System 2.0 (FNGS) [22], was developed, allowing voluntary movements of the different facial areas and synkineses to be assessed separately. Symmetry at rest was still linked to voluntary movement assessment. FNGS coverage amongst published studies has been scant.

The Sunnybrook facial grading system (SB) [23, 24], on the other hand, seems to have grown in popularity amongst investigators [20, 25]. It is a regional weighted system, that takes into consideration the resting symmetry of the face, the degree of voluntary movement, and also synkineses regionally. The composite score varies from 0 to 100 , where 0 stands for total paralysis and 100 for normal facial function.

The first aim of this study was to determine the long-term FP outcome of RHS by face-to-face grading by using the three above-mentioned grading scales concomitantly. The second aim was to compare the applicability of the grading scales and the results received. Third, we wanted to know whether patient self-assessed FP outcome results varied from gradings performed by the investigator. Finally, our aim was to compare the face-to-face assessed FP outcome grade to the initial FP grade in association with the medication patients received and medication start time at RHS onset.

\section{Materials and methods}

A computer search from January 1996 to January 2013 was performed in our tertiary referral center: ICD codes for shingles with any complication or supplementary diagnosis with concomitant FP diagnosis were used. Patients with varicellazoster blisters in the head and neck area within 1 month prior or after, or concomitantly with, palsy onset were included in the study.

Patients were sent a questionnaire about their RHS [11]. They were asked to self-assess their RHS FP outcome and were invited to come to one follow-up visit, where their facial function was graded by the corresponding author with HB, FNGS, and SB concomitantly.

We gathered information from the patient records on initial FP grade, what medication was used and when it was started in relation to RHS onset.

The study group was composed of patients fulfilling the diagnosis requirements, with a minimum of one year from the RHS onset, answering the questionnaire, and being able to come to a follow-up visit.

FP grading methods at initial visit varied in the patient records, and both $\mathrm{HB}$ and SB grading scales had been used. For study purposes, to be able to compare SB results to HB and FNGS results, SB grades were converted to HB grades according to a conversion table: SB 100 converting to $\mathrm{HB}$ I; SB 70-99 to HB II; SB 43-69 to HB III; SB 26-42 to HB IV; SB $13-25$ to HB V; and SB 0-12 to HB VI [26].

The Helsinki University Hospital Ethics Committee approved the study and institutional research approval was granted. All patients gave their written informed consent.

We used SPSS (IBM Corp., Armonk, NY, USA) versions 22-24 for statistical analyses. We used descriptive statistics to summarize the frequencies, proportions, means or medians, and ranges.

\section{Results}

\section{Patients}

Computer search revealed 120 RHS patients: 71 women, 49 men. At the time of the study, 8 of the 120 patients had died and four could not be reached. The remaining 108 patients were sent a questionnaire about their RHS and were invited for one follow-up visit for facial function grading. Of these, 81 answered the questionnaire (52 women, 29 men) and 57 (41 women, 16 men) came for a follow-up visit. A caregiver of additional three patients informed that due to the patient's illnesses, the patient was no longer capable of answering the questionnaire or to come for a follow-up visit.

We have previously published the results of the retrospective chart study (120 patients) and the patient questionnaire study (81 patients): medical treatment, blister location and time to FP, hearing loss and its outcome, other adjoining symptoms, and outcome of FP on grounds of patient charts, and patient self-assessment [11]. In the current study, we concentrated on the face-to-face assessed long-term FP outcome of those 57 patients coming to the follow-up visit. Other characteristics of their RHS were included in the results of the previous study and are not repeated here.

Altogether 26/57 (46\%) patients experienced FP on the right, and $31 / 57$ (54\%) on the left. Age median at RHS onset was 48.8 years (range 6.9-79.7): for women 50.2 
(range 19.9-79.7) for men 45.5 (range 6.9-71.5). Two of the patients were 16 years or younger at RHS onset. The median follow-up time was 6.6 years (range 1-17.1). 6 of the 57 patients $(10.5 \%)$ had an illness or medication that made them immunocompromised and could have predisposed the patient to RHS. No one had a history of previous RHS or relatives with RHS. One patient had experienced FP and total recovery a long time before. Six patients had a relative with FP history.

\section{The applicability of the grading scales}

The use of FNGS and HB revealed inconsistencies. With $\mathrm{HB}$, each grades I-VI includes definitions for what the grade stands for with respect to voluntary movement in the forehead, eye, and mouth as well as the level of symmetry at rest, and synkineses; all of these combined to one representing grade. Nevertheless, voluntary movement recovery levels in different parts of the face differ sometimes greatly. In this study, placing the patient to only one HB grade was impossible in many cases. Even if one compromised voluntary movement grade was set between forehead, eye, and mouth, the resting symmetry and/or synkineses status was still many times in disagreement with the grade best representing the voluntary movement status. Even though HB grading was carried out throughout the study with additional notes to mark the discrepancies, the results are not presented here, since $37 / 57$ (65\%) of the patients would have needed two or more HB grades to represent their FP outcome.

FNGS worked better than HB, but the symmetry at rest results were in disagreement with the voluntary movement results (to which they are anchored in this grading system) with $17 / 57$ (30\%) of the patients. The voluntary movement outcome was considered more important and asymmetry at rest had to be disregarded in these cases, resulting in better outcome results than in reality.

SB was the most applicable of the three grading scales used since it allows regional assessment of all variables; voluntary movement, symmetry at rest, and synkineses.

\section{Medical treatment}

At RHS onset, all but one of the 57 patients were prescribed antiviral medication; 28 (49\%) were also prescribed concomitant corticosteroids (Table 1). One patient admitted not taking either of the prescribed medicines and was placed in the "no medication" group for the outcome results.

Of the 57 patients, $50(88 \%)$ received their medication within 48 h, $1(1.8 \%)$ within 72 h, and $6(10.5 \%)$ over $72 \mathrm{~h}$ from the onset of RHS or no medication at all (Table 1).

\section{Comparison of long-term FP outcome to initial medication}

The patient number in this study was too small to draw statistically reliable conclusions whether the type or dosing of the used medication played any role in the outcome of FP. In our previous study [11], the outcome stayed the same as long as the medication was started within $72 \mathrm{~h}$ of the RHS onset. The outcome was worse with those receiving no medication or starting the medication over $72 \mathrm{~h}$ from RHS onset.

The same result trend could be seen in this study (a subgroup of the previous study; individual patient outcomes not shown). The number of patients receiving their medication later than $72 \mathrm{~h}$ or not taking any medication at all was low, $6 / 57(10.5 \%)$, but none recovered totally and $3 / 6(50 \%)$ recovered to having only slight sequelae.

\section{Comparison of the long-term FP outcome to initial FP grade}

Of these 57 graded patients, $28(49 \%)$ had a mention of the FP grade at the initial visit in their charts. There were 12 patients with HB V-VI; 5 HB IV; 5 HB III; and 6 HB II (Table 1).

The face-to-face assessment SB outcome results have been converted here to HB grades (see Methods) to be able to compare to the base line HB grades. From HB V-VI, 7/12 (58.5\%) patients recovered to HB I-II, 4 even with an SB grade of 96 (of 100) or better, which is an excellent result; $4 / 12(33.3 \%)$ to HB III; and 1/12 (8.3\%) to HB IV. From HB IV, $4 / 5$ (80\%) recovered to HB I-II; $1 / 5$ (20\%) to HB III. From HB III and HB II, all 11 patients recovered to HB I-II. Those initially with mild palsy of HB II recovered all to level 90 or better with SB grading (Table 1).

\section{Long-term outcome of all 57 patients}

SB face-to-face long-term FP outcome voluntary movement recovery results are seen in Table 2 and the final total scores in Table 3. Converting the SB total score results to HB grade: $17 / 57$ (30\%) recovered to HB grade I; 31/57 (54\%) to HB II; $6 / 57$ (11\%) to HB III; and $3 / 37$ (5\%) to HB IV. Of those 33 patients that had total voluntary movement recovery (SB 100), 12/33 (36\%) had slight synkinesis that affected their total score in SB to be worse than 100 (Table 3). Four of these patients also had slight asymmetry of the face at rest. An additional 4/33 (12\%) patients with total voluntary movement recovery had only asymmetry at rest, and no synkinesis. 
Table 1 Long-term outcome of Ramsay Hunt syndrome facial palsy compared to medication and its star time: initial facial palsy grade (known for 28 patients), follow-up visit facial palsy grade (57 patients), and patient's self-assessment (57 patients)

\begin{tabular}{|c|c|c|c|c|c|}
\hline \multirow[t]{2}{*}{$\begin{array}{l}\text { Medication at Ramsay Hunt syndrome } \\
\text { onset }\end{array}$} & \multirow[t]{2}{*}{$\begin{array}{l}\text { Num- } \\
\text { ber of } \\
\text { patients }\end{array}$} & \multicolumn{4}{|c|}{$\begin{array}{l}\text { Medication onset time from Ramsay Hunt diagnosis/patient number; initial HB } \\
\text { grade } \rightarrow \text { follow-up visit assessed HB grade } \text { gratient number; patient self-graded outcome }^{\ddagger} / \\
\text { patient number }\end{array}$} \\
\hline & & $\leq 24 \mathrm{~h}$ & $\leq 48 \mathrm{~h}$ & $\leq 72 \mathrm{~h}$ & $>72 \mathrm{~h}$ \\
\hline Valaciclovir $1 \mathrm{~g} \times 3 \times 7$ orally & 9 & $\begin{array}{l}8 ; \\
\mathrm{HB} \text { VI } \rightarrow \mathrm{HB} \mathrm{I} / 1 ; 2 / 1 \\
\mathrm{HB} ? \rightarrow \mathrm{HB} \mathrm{I} / 3 ; 1 / 2,2 / 1 \\
\mathrm{HB} ? \rightarrow \mathrm{HB} \mathrm{II} / 3 ; 2 / 3 \\
\mathrm{HB} \mathrm{III} \rightarrow \mathrm{HB} \mathrm{II} / 1 ; 1 / 1\end{array}$ & & $\begin{array}{l}1 ; \\
\mathrm{HB} \\
? \rightarrow \mathrm{HB} \\
\mathrm{I} / 1 ; 1 / 1\end{array}$ & \\
\hline Valaciclovir orally, dosing unclear & 1 & $\begin{array}{l}1 ; \\
\mathrm{HB} \mathrm{V} \rightarrow \mathrm{HB} \mathrm{II} / 1 ; 2 / 1\end{array}$ & & & \\
\hline $\begin{array}{l}\text { Valaciclovir } 1 \mathrm{~g} \times 3 \times 7 \text { orally }+ \text { corti- } \\
\text { costeroid }^{\mathbb{I I}}\end{array}$ & 24 & $\begin{array}{l}22 ; \\
\mathrm{HB} \mathrm{II} \rightarrow \mathrm{HB} \mathrm{II} / 1 ; 1 / 1 \\
\mathrm{HB} \mathrm{III} \rightarrow \mathrm{HB} \mathrm{I} / 2 ; 1 / 2 \\
\mathrm{HB} \mathrm{III} \rightarrow \mathrm{HB} \mathrm{II} / 1 ; 4 / 1 \\
\mathrm{HB} \mathrm{IV} \rightarrow \mathrm{HB} \mathrm{II}(\mathrm{I}) / 1 ; 1 / 1 \\
\mathrm{HB} \mathrm{IV} \rightarrow \mathrm{HB} \mathrm{II} / 2 ; 2 / 2 \\
\mathrm{HB} \mathrm{V} \rightarrow \mathrm{HB} \mathrm{II} / 1 ; 2 / 1 \\
\mathrm{HB} \mathrm{V} \rightarrow \mathrm{HB} \mathrm{III} / 1 ; 3 / 1 \\
\mathrm{HB} \mathrm{VI} \rightarrow \mathrm{HB} \mathrm{II} / 1 ; 3 / 1 \\
\mathrm{HB} \mathrm{VI} \rightarrow \mathrm{HB} \mathrm{IV} / 1 ; 3 / 1 \\
\mathrm{HB} ? \rightarrow \mathrm{HB} \mathrm{I} / 4 ; 1 / 4 \\
\mathrm{HB} ? \rightarrow \mathrm{HB} \mathrm{II}(\mathrm{I}) / 1 ; 1 / 1 \\
\mathrm{HB} ? \rightarrow \mathrm{HB} \mathrm{II} / 5 ; 2 / 4,3 / 1 \\
\mathrm{HB} ? \rightarrow \mathrm{HB} \mathrm{IV}(\mathrm{V}) / 1 ; 3 / 1\end{array}$ & $\begin{array}{l}1 ; \\
\mathrm{HB} I I \rightarrow \mathrm{HB} I / 1 ; 1 / 1\end{array}$ & & $\begin{array}{l}1 ; \\
\mathrm{HB} \mathrm{V} \rightarrow \mathrm{HB} \mathrm{III} / 1 ; 3 / 1\end{array}$ \\
\hline Acyclovir $800 \mathrm{mg} \times 5 \times 7$ orally & 4 & $\begin{array}{l}3 \\
\mathrm{HB} \mathrm{III} \rightarrow \mathrm{HB} \mathrm{I} / 1 ; 2 / 1 \\
\mathrm{HB} \mathrm{IV} \rightarrow \mathrm{HB} \mathrm{III} / 1 ; 2 / 1 \\
\mathrm{HB} ? \rightarrow \mathrm{HB} \mathrm{I} / 1 ; 1 / 1\end{array}$ & & & $\begin{array}{l}\text { HB } \mathrm{VI} \rightarrow \mathrm{HB} \mathrm{II} / 1 ; 2 / 1 \\
\text { H }\end{array}$ \\
\hline $\begin{array}{l}\text { Acyclovir orally, dosing under } \\
800 \mathrm{mg} \times 5 \times 7 \text { or unclear }\end{array}$ & 4 & $\begin{array}{l}3 \\
\mathrm{HB} \text { IV } \rightarrow \mathrm{HB} \mathrm{I} / 1 ; 1 / 1 \\
\mathrm{HB} ? \rightarrow \mathrm{HB} \mathrm{II} / 1 ; 1 / 1 \\
\mathrm{HB} ? \rightarrow \mathrm{HB} \mathrm{II}(\mathrm{I}) / 1 ; 2 / 1\end{array}$ & $\begin{array}{l}1 ; \\
\mathrm{HB} ? \rightarrow \mathrm{HB} \mathrm{II} / 1 ; 3 / 1\end{array}$ & & \\
\hline $\begin{array}{l}\text { Acyclovir under } 10 \mathrm{mg} / \mathrm{kg} / \text { day } \times 3 \text { or } \\
\text { unclear intra venous }\end{array}$ & 1 & $\begin{array}{l}1 ; \\
\mathrm{HB} \mathrm{II} \rightarrow \mathrm{HB} \mathrm{I} / 1 ; 1 / 1\end{array}$ & & & \\
\hline $\begin{array}{l}\text { Acyclovir dosing under } 800 \mathrm{mg} \times 5 \times 7 \\
\text { orally or under } 10 \mathrm{mg} / \mathrm{kg} / \text { day } \times 3 \text { intra } \\
\text { venous }+ \text { corticosteroid }^{\text {II }}\end{array}$ & 2 & $\begin{array}{l}2 ; \\
\mathrm{HB} \mathrm{V} \rightarrow \mathrm{HB} \mathrm{III} / 1 ; 2 / 1 \\
\mathrm{HB} \mathrm{II} \rightarrow \mathrm{HB} \mathrm{I} / 1 ; 1 / 1\end{array}$ & & & \\
\hline $\begin{array}{l}\text { Acyclovir } 10 \mathrm{mg} / \mathrm{kg} / \text { day } \times 3 \text { intra } \\
\text { venous }\end{array}$ & 8 & $\begin{array}{l}7 \\
\mathrm{HB} \mathrm{V} \rightarrow \mathrm{HB} \mathrm{II} / 2: 2 / 1,3 / 1 \\
\mathrm{HB} \mathrm{VI} \rightarrow \mathrm{HB} \mathrm{III} / 1 ; 2 / 1 \\
\mathrm{HB} ? \rightarrow \mathrm{HB} \mathrm{II} / 4 ; 1 / 1,2 / 2,4 / 1\end{array}$ & & & $\begin{array}{l}1 ; \\
\mathrm{HB} \mathrm{II} \rightarrow \mathrm{HB} \mathrm{II} / 1 ; 3 / 1\end{array}$ \\
\hline $\begin{array}{l}\text { Acyclovir } 10 \mathrm{mg} / \mathrm{kg} / \text { day } \times 3 \text { intra } \\
\text { venous }+ \text { corticosteroid }{ }^{\mathbb{I I}}\end{array}$ & 2 & $\begin{array}{l}1 ; \\
\mathrm{HB} \mathrm{II} \rightarrow \mathrm{HB} \text { II(I)/1; } 2 / 1\end{array}$ & & & $\begin{array}{l}1 ; \\
\mathrm{HB} ? \rightarrow \mathrm{HB} \text { IV } / 1 ; 3 / 1\end{array}$ \\
\hline No medication & 2 & & & & $\begin{array}{l}2 ; \\
\mathrm{HB} ? \rightarrow \mathrm{HB} \text { II } / 1 ; 2 / 1 \\
\mathrm{HB} ? \rightarrow \mathrm{HB} \mathrm{III}(\mathrm{IV}) / 1 ; 3 / 1\end{array}$ \\
\hline
\end{tabular}

${ }^{\dagger}$ Initial facial palsy grade was available from 28/57 patient records, graded by House-Brackmann scale (HB) or Sunnybrook scale (SB), latter converted here to HB grades. Outcome was graded by SB and Facial Nerve Grading System 2.0 (FNGS) converted here to HB grades. When SB and FNGS differ, the latter is in parentheses

†Facial palsy outcome by patient’s own assessment: $1=$ totally recovered; $2=$ slight sequelae; $3=$ obvious sequelae; $4=$ severe sequelae

${ }^{\mathbb{I}}$ Corticosteroid usually Prednisolon $60 \mathrm{mg} /$ day with tapering dosing $10 \mathrm{mg} /$ day after 5 days for 10 days or Medrol $32 \mathrm{mg}$ or $64 \mathrm{mg} / \mathrm{day}$ for 7-10 days 
Table 2 Sunnybrook voluntary movement scores for 57 follow-up patients

\begin{tabular}{ll}
\hline Sunnybrook score & Patient number/\% \\
\hline 100 & $33 / 57.9$ \\
$90-99$ & $10 / 17.5$ \\
$80-89$ & $6 / 10.5$ \\
$70-79$ & $2 / 3.5$ \\
$60-69$ & $4 / 7.0$ \\
$50-59$ & $1 / 1.8$ \\
$40-49$ & $1 / 1.8$ \\
\hline
\end{tabular}

Table 3 Sunnybrook total scores for 57 follow-up patients

\begin{tabular}{ll}
\hline Sunnybrook score & Patient number/\% \\
\hline 100 & $17 / 29.8$ \\
$90-99$ & $20 / 35.1$ \\
$80-89$ & $6 / 10.5$ \\
$70-79$ & $5 / 8.8$ \\
$60-69$ & $2 / 3.5$ \\
$50-59$ & $3 / 5.3$ \\
$40-49$ & $2 / 3.5$ \\
$30-39$ & $1 / 1.8$ \\
$20-29$ & $1 / 1.8$ \\
\hline
\end{tabular}

Altogether, synkineses were detected by SB in $34 / 57$ $(60 \%)$ patients, asymmetry at rest in 23/57 (40\%), and both or either one in $38 / 57$ (67\%).

Overall, $84 \%$ of the patients with SB experienced a good outcome (SB 70-100, converting to HB I-II).

FNGS (used as described previously: e.g. disregarding asymmetry when in disagreement with the voluntary movement outcome) resulted in 21/57 (37\%) total recoveries (grade 1); 27/57 (47\%) good recovery (grade 2); 5/57 (9\%) grade $3 ; 3 / 57$ (5\%) grade 4 ; and $1 / 57$ (2\%) grade 5. Altogether, a good recovery (grades 1 and 2) was achieved for 48/57 (84\%) patients.

Thus, SB and FNGS (with adjustments) resulted in 30\% and $37 \%$, respectively, total recovery and both in $84 \%$ good recovery outcome results.

\section{Comparison of patient self-assessment to grading by the investigator}

Of those 17 patients, who were assessed by the investigator to be totally recovered, three (18\%) assessed themselves as incompletely recovered, reporting slight sequelae; tightness of the face, occasional numbness of the face, asymmetry, and functional defects (Table 1). In addition, two patients who were placed in HB grade II (SB 70-99; their SB grades 72 and 89) assessed themselves having severe sequelae
(Table 1). Altogether, 5/57 (9\%) self-assessed themselves worse recovered than the investigator's assessment. On the other hand, 6/57 (10\%), who were graded to have slight synkinesis, slight asymmetry at rest, and/or slight motor dysfunction, had considered themselves as totally recovered (Table 1). Thus, 11/57 (19\%) of the self-assessment FP outcome results differed from the investigator's assessment.

\section{Discussion}

\section{Grading}

All studies assessing FP outcome have the same weakness and difficulty of lacking a reliable method of grading [20]. All grading systems in wider clinical use today are subjective. Objective methods are not yet in everyday use or are only usable for a certain facial region [27-29]. Many of the studies on grading methods have understandably also used video recordings of the patients. Researchers have shown, however, that grading the facial function face-to-face with the patient as compared to grading from a video affects the results obtained, especially concerning the grading of synkinesis [30]. Thus, there is a definite need for an affordable, easy to use, reliable, and objective grading method.

We used three grading scales concomitantly to compare their clinical suitability. Trying to assess only one HB grade to represent the FP outcome was impossible with most patients. This observation leads to critically view the previously reported HB outcomes of FP studies. There is no way of knowing how systematically synkineses and resting symmetry have been included in these assessments. By saying this, we want to draw the reader's attention to the fact, that using FNGS, and especially SB grading, we are most probably being more precise and getting worse results than if we used HB in a "liberal way", assessing the patient with a compromised HB grade and ignoring conflicting synkinesis or asymmetry findings. The use of HB mostly reflects patient's voluntary movement recovery and is a compromise between the different areas of the face. We also claim, that the HB grading system has been mainly used as a linear grading from I to VI, with assessors not so much paying attention to what each grade's definition describes and demands. This thought has arisen from the observation that if those definitions are followed, the use of HB grading becomes impossible because of the discrepancy of findings. HB not being specific enough and recognizing that originally it was not even meant to do so, have been previously shown by our own studies [19, 26] and by many colleagues as well [20, 21, 31].

Although FNGS worked better in this study than HB, the use of FNGS needed adjustments and inevitable disregard of certain findings. Previously, it has been observed that 
there are no published studies on intraobserver reliability of FNGS [20].

Based on the results acquired from this and the previous studies [20,25], we suggest that of these three grading scales, SB should be the one recommended to be used.

In their self-assessment, part of the patients assessed their FP outcome differently from the assessment by the investigator. The face can look and function symmetrically, but still feel stiff or weak. This phenomenon of discrepancy between self-assessments vs investigator gradings has been shown in the previous studies [32,33]. Hence, every patient's illness and needs are unique, no matter how similar they look from the outside.

\section{FP outcome}

In our study, the long-term FP outcome "good recovery" was obtained by $84 \%$ of the patients. The result was very good, but still in concordance with studies where medical therapy (antivirals and corticosteroids) has been used [4, 12-14, 34-36]. Even though in our study almost all patients received antiviral therapy, only half received simultaneous corticosteroid treatment. The addition did not seem to affect the FP outcome. The patient number was too small to draw further conclusions about the different medical treatment modalities. These outcome results far exceed those seen prior to the application of antiviral medication [7, 8]. With these outcome results, the previously considered, much worse outcome of RHS FP compared to Bell's palsy does not seem to be so drastic anymore. If we study Bell's palsy patients (that have received corticosteroid treatment) meticulously after a minimum of one year from the palsy onset with the SB grading method, about $30 \%$ will have sequelae [37]. We could say, that the outcome results of Bell's palsy and RHS FP have converged with each other and the diagnosis of RHS is no longer so devastating to the patient as before.

\section{Strengths and limitations}

The strength of this study was the novel follow-up visit assessment by one investigator of the long-term (median follow-up time over 6 years) outcome of RHS FP. We also had a fairly large group of RHS patents answer the questionnaire and come to the visit. A strength was also that the FP grade evaluations at the visit were done by only one investigator, so the gradings were comparable to each other.

A limitation was that FP gradings at RHS onset were not standardized and were collected from patient records retrospectively. The time the patient was first seen and evaluated after FP onset also varied amongst patients. The low patient number unfortunately allowed only suggestive conclusions to be drawn about the initial medical treatment and FP outcome.

\section{Conclusions}

Is it time to wean ourselves from the use of the HB grading system; do we get a false sense of accuracy, even though the given grade is a result of compromise and individual interpretation? In this study, FNGS also needed ignorance of some of the sequelae to be executable. Of the three scales used, SB was the most applicable.

The results also emphasized the importance of recognizing RHS, since with antivirus medication the outcome of RHS FP starts to resemble that of Bell's palsy and gives hope to patients afflicted by RHS.

Acknowledgements Open access funding provided by University of Helsinki including Helsinki University Central Hospital.

Funding This work was supported by Helsinki University Hospital Research Funds. The funding source was not involved in the study design; in the collection, analysis, and interpretation of data; in the writing of the report; and in the decision to submit this manuscript for publication.

\section{Compliance with ethical standards}

Conflict of interest The authors declare that they have no conflict of interest.

Ethical approval The Ethics Committee of the Helsinki University Hospital approved the study and institutional research approval was granted. All patients gave their written informed consent.

Open Access This article is licensed under a Creative Commons Attribution 4.0 International License, which permits use, sharing, adaptation, distribution and reproduction in any medium or format, as long as you give appropriate credit to the original author(s) and the source, provide a link to the Creative Commons licence, and indicate if changes were made. The images or other third party material in this article are included in the article's Creative Commons licence, unless indicated otherwise in a credit line to the material. If material is not included in the article's Creative Commons licence and your intended use is not permitted by statutory regulation or exceeds the permitted use, you will need to obtain permission directly from the copyright holder. To view a copy of this licence, visit http://creativecommons.org/licenses/by/4.0/.

\section{References}

1. Sweeney CJ, Gilden DH (2001) Ramsay Hunt syndrome. J Neurol Neurosurg Psychiatry 71(2):149-154

2. Alicandri-Ciufelli M, Aggazzotti-Cavazza E, Genovese E, Monzani D, Presutti L (2012) Herpes zoster oticus: a clinical model for a transynaptic, reflex pathways, viral transmission hypotheses. Neurosci Res 74(1):7-9 
3. Kim YH, Chang MY, Jung HH et al (2010) Prognosis of Ramsay Hunt syndrome presenting as cranial polyneuropathy. Laryngoscope 120(11):2270-2276

4. Shim HJ, Jung H, Park DC, Lee JH, Yeo SG (2011) Ramsay Hunt syndrome with multicranial nerve involvement. Acta Otolaryngol 131(2):210-215

5. Kennedy PGE, Cohrs RJ (2010) Varicella-zoster virus human ganglionic latency: a current summary. J Neurovirol 16(6):411-418

6. Aizawa H, Ohtani F, Furuta Y, Sawa H, Fukuda S (2004) Variable patterns of varicella-zoster virus reactivation in Ramsay Hunt syndrome. J Med Virol 74(2):355-360

7. Peitersen E (2002) Bell's palsy: the spontaneous course of 2,500 peripheral facial nerve palsies of different etiologies. Acta Otolaryngol Suppl 549:4-30

8. Devriese PP, Moesker WH (1988) The natural history of facial paralysis in herpes zoster. Clin Otolaryngol Allied Sci 13(4):289-298

9. Robillard RB, Hilsinger RL Jr, Adour KK (1986) Ramsay Hunt facial paralysis: clinical analyses of 185 patients. Otolaryngol Head Neck Surg 95(3 Pt 1):292-297

10. Hato N, Kisaki H, Honda N, Gyo K, Murakami S, Yanagihara N (2000) Ramsay Hunt syndrome in children. Ann Neurol 48(2):254-256

11. Kanerva M, Jones S, Pitkaranta A (2020) Ramsay Hunt syndrome: characteristics and patient self-assessed long-term facial palsy outcome. Eur Arch Otorhinolaryngol 227(4):1235-1245. https:// doi.org/10.1007/s00405-020-05817-y

12. Coulson S, Croxson GR, Adams R, Oey V (2011) Prognostic factors in herpes zoster oticus (Ramsay Hunt syndrome). Otol Neurotol 32(6):1025-1030

13. Uri N, Greenberg E, Kitzes-Cohen R, Doweck I (2003) Acyclovir in the treatment of Ramsay Hunt syndrome. Otolaryngol Head Neck Surg 129(4):379-381

14. Murakami S, Hato N, Horiuchi J, Honda N, Gyo K, Yanagihara N (1997) Treatment of Ramsay Hunt syndrome with acyclovirprednisone: significance of early diagnosis and treatment. Ann Neurol 41(3):353-357

15. de Ru JA, van Benthem PP (2011) Combination therapy is preferable for patients with Ramsay Hunt syndrome. Otol Neurotol 32(5):852-855

16. Bean B, Braun C (1982) Balfour HHJ (1982) acyclovir therapy for acute herpes zoster. Lancet 2(8290):118-121

17. Whitley RJ (2009) A 70-year-old woman with shingles: review of herpes zoster. JAMA 302(1):73-80

18. House JW, Brackmann DE (1985) Facial nerve grading system. Otolaryngol Head Neck Surg 93(2):146-147

19. Kanerva M, Poussa T, Pitkaranta A (2006) Sunnybrook and House-Brackmann facial grading systems: Intrarater repeatability and interrater agreement. Otolaryngol Head Neck Surg 135(6):865-871

20. Fattah AY, Gurusinghe ADR, Gavilan J et al (2015) Facial nerve grading instruments: systematic review of the literature and suggestion for uniformity. Plast Reconstr Surg 135(2):569-579

21. Scheller C, Wienke A, Tatagiba $M$ et al (2017) Interobserver variability of the House-Brackmann facial nerve grading system for the analysis of a randomized multi-center phase III trial. Acta Neurochir (Wien) 159(4):733-738

22. Vrabec JT, Backous DD, Djalilian HR et al (2009) Facial nerve grading system 2.0. Otolaryngol Head Neck Surg 140(4):445-450
23. Neely JG, Cherian NG, Dickerson CB, Nedzelski JM (2010) Sunnybrook facial grading system: reliability and criteria for grading. Laryngoscope 120(5):1038-1045

24. Ross BG, Fradet G, Nedzelski JM (1996) Development of a sensitive clinical facial grading system. Otolaryngol Head Neck Surg 114(3):380-386

25. Berner JE, Kamalathevan P, Kyriazidis I, Nduka C (2019) Facial synkinesis outcome measures: a systematic review of the available grading systems and a Delphi study to identify the steps towards a consensus. J Plast Reconstr Aesthet Surg 2(6):946-963

26. Kanerva M, Jonsson L, Berg T et al (2011) Sunnybrook and House-Brackmann systems in 5397 facial gradings. Otolaryngol Head Neck Surg 144(4):570-574

27. Banks CA, Jowett N, Hadlock TA (2017) Test-retest reliability and agreement between in-person and video assessment of facial mimetic function using the eFACE facial grading system. JAMA Facial Plast Surg 19(3):206-211

28. Monini S, Filippi C, Marinozzi F et al (2019) Validation of the objective assessment of facial movement with a new softwarebased system. Acta Otolaryngol (Stockh) 139(5):456-460

29. Katsumi S, Esaki S, Hattori K, Yamano K, Umezaki T, Murakami S (2015) Quantitative analysis of facial palsy using a three-dimensional facial motion measurement system. Auris Nasus Larynx 42(4):275-283

30. Tan JR, Coulson S, Keep M (2019) Face-to-face versus video assessment of facial paralysis: Implications for telemedicine. J Med Internet Res 21(4):e11109

31. Coulson SE, Croxson GR, Adams RD, O’Dwyer NJ (2005) Reliability of the "Sydney," "Sunnybrook," and "House-Brackmann" facial grading systems to assess voluntary movement and synkinesis after facial nerve paralysis. Otolaryngol Head Neck Surg 132(4):543-549

32. Gyori E, Przestrzelski C, Pona I et al (2018) Quality of life and functional assessment of facial palsy patients: a questionnaire study. Int J Surg 55:92-97

33. Ikeda M, Nakazato H, Hiroshige K, Abiko Y, Sugiura M (2003) To what extent do evaluations of facial paralysis by physicians coincide with self-evaluations by patients: comparison of the Yanagihara method, the House-Brackmann method, and self-evaluation by patients. Otol Neurotol 24(2):334-338

34. Kinishi M, Amatsu M, Mohri M, Saito M, Hasegawa T, Hasegawa S (2001) Acyclovir improves recovery rate of facial nerve palsy in Ramsay Hunt syndrome. Auris Nasus Larynx 28(3):223-226

35. Zainine R, Sellami M, Charfeddine A, Beltaief N, Sahtout S, Besbes G (2012) Ramsay Hunt syndrome. Eur Ann Otorhinolaryngol Head Neck Dis 129(1):22-25

36. Kim HJ, Jung J, Kim SS, Byun JY, Park MS, Yeo SG (2017) Comparison of acyclovir and famciclovir for Ramsay Hunt syndrome. Otol Neurotol 38(5):754-758

37. Engstrom M, Berg T, Stjernquist-Desatnik A et al (2008) Prednisolone and valaciclovir in Bell's palsy: a randomised, double-blind, placebo-controlled, multicentre trial. Lancet Neurol 7(11):993-1000

Publisher's Note Springer Nature remains neutral with regard to jurisdictional claims in published maps and institutional affiliations. 